\title{
Spectrophotometric method for simultaneous determination of valsartan and substances from the group of statins in binary mixtures
}

\author{
MARIUSZ STOLARCZYK* \\ ANNA APOLA \\ ANNA MAŚLANKA \\ ANNA KWIECIEŃ \\ WŁODZIMIERZ OPOKA \\ Department of Inorganic \\ and Analytical Chemistry \\ Jagiellonian University Medical \\ College, Faculty of Pharmacy \\ 30-688 Kraków, Poland
}

Accepted June 6, 2017

Published online August 25, 2017

\begin{abstract}
Applicability of derivative spectrophotometry for the determination of valsartan in the presence of a substance from the group of statins was checked. The obtained results indicate that the proposed method may be effective by using appropriate derivatives: for valsartan and fluvastatin - D1, D2 and D3, for valsartan and pravastatin - D1 and D3, for valsartan and atorvastatin - D2 and D3. The method was characterized by high sensitivity and accuracy. Linearity was maintained in the following ranges: 9.28-32.48 $\mu \mathrm{g} \mathrm{mL} \mathrm{m}^{-1}$ for valsartan, $8.16-28.56 \mu \mathrm{g} \mathrm{mL}^{-1}$ for fluvastatin, $14.40-39.90 \mu \mathrm{g} \mathrm{mL}^{-1}$ for atorvastatin and 9.60-48.00 $\mu \mathrm{g} \mathrm{mL}^{-1}$ for pravastatin. Determination coefficients were in the range of 0.989-0.999 depending on the analyte and the order of derivative. The precision of the method was high with RSD from 0.1 to $2.5 \%$ and recovery of individual components was within the range of $100 \pm 5 \%$. The developed method was successfully applied to the determination of valsartan combined with fluvastatin, atorvastatin and pravastatin in laboratory prepared mixtures and in pharmaceutical preparations.
\end{abstract}

Keywords: valsartan, atorvastatin, fluvastatin, pravastatin, derivative spectrophotometry

Valsartan (VAL), (S)-3-methyl-2-(N-\{[2'-(2H-1,2,3,4-tetrazol-5-yl)biphenyl-4-yl] methyl\} pentanamido) butanoic acid, is a cardioprotective drug, specific, selective angiotensin II receptor antagonist (ARB, sartan), type $\mathrm{AT}_{1}$. Fluvastatin (FLU), (3R,5S,6E)-7-[3-(4-fluorophenyl)-1-(propan-2-yl)-1H-indol-2-yl]-3,5-dihydroxyhept-6-enoic acid, pravastatin (PRV), $(3 R, 5 R)-3,5$-dihydroxy-7-((1R,2S,6S,8R, 8aR)-6-hydroxy-2-methyl-8- $\{[(2 S)-2$-methylbutanoyl]oxy\}-1,2,6,7,8,8a-hexahydronaphtha-len-1-yl)-heptanoic acid, and atorvastatin (ATR), (3R,5R)-7-[2-(4-fluorophenyl)-3-phenyl-4-(phenylcarbamoyl)-5-propan-2-yl-pyrrol-1-yl]-3,5-dihydroxy heptanoic acid, belong to the group of statins (STAT), selective inhibitors of 3-hydroxy-3methylglutaryl coenzyme A reductase (HMG-CoA reductase). They are commonly used

\footnotetext{
*Correspondence; e-mail: mariusz.stolarczyk@uj.edu.pl
} 
<smiles>CCCCC(=O)N(Cc1ccc(-c2ccccc2-c2nnn[nH]2)cc1)C(C(=O)O)C(C)C</smiles>

Valsartan

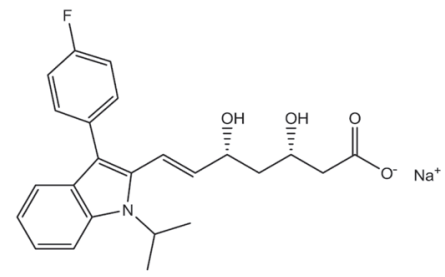

Fluvastatin

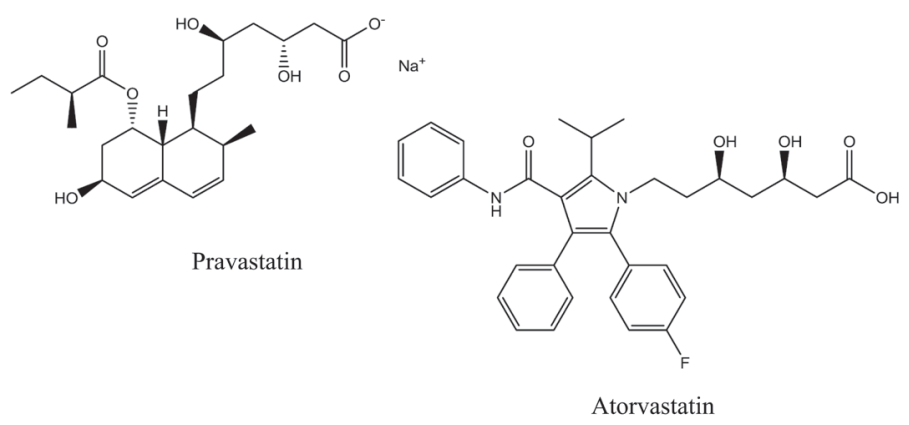

Fig. 1. Chemical structures of valsartan (VAL), fluvastatin (FLU), pravastatin (PRV) and atorvastatin (ATR).

as primary hypolipidemic drugs. Structural formulas of the tested substances are shown in Fig. 1.

Substances from the group of angiotensin II receptor antagonists (ARB) and inhibitors of 3-hydroxy-3-methylglutaryl-coenzyme A reductase are commonly used in the treatment of hypertension with concomitant dyslipidemia. Extensive research on the use of VAL and STAT demonstrated that co-administration of small doses of these substances has a beneficial effect on improving the state of the arteries in patients who have changes associated with age (1), or in the case of changes in the arteries of patients with diagnosed diabetes (2). The beneficial effect of the combination of these substances on the reduction of oxidative stress in combination with anti-inflammatory effect was also observed when compared with the administration of VAL alone (3).

Recent studies of polytherapy with VAL and STAT show that this combination has a synergistic effect and may significantly increase the effectiveness of antihypertensive activity of VAL (4).

In scientific literature, we can find many monographs on the analysis of sartans, determination of individual substances, mixtures or combinations with other substances in laboratory prepared mixtures, pharmaceutical preparations and biological material, usually blood serum or urine. The most commonly used methods for this purpose were chromatographic methods such as HPTLC and $\operatorname{TLC}(5,6), \operatorname{LC}(7,8), \operatorname{HPLC}(9)$ and CE $(10,11)$. The UPLC-MS/MS method was applied for simultaneous determination of telmisartan and hy- 
drochlorotiazide in human plasma (12). VAL was also determined by a spectrophotometric method $(13,14)$. Atorvastatin was determined in tablets by a microwell-based spectrophotometric method (15). Analytical aspects relating to the ARB were also reviewed $(16,17)$.

Chromatographic methods such as HPLC with spectrophotometric detection were successfully used for the determination of inhibitors of 3-hydroxy-3-methylglutaryl coenzyme A reductase (18-20). Electroanalytical methods (21, 22) and spectrophotometric methods were also applied (23). Pharmacokinetics of statins, their metabolites and impurities were described in review papers by Pasha et al. (24) and Ertürk et al. (25).

Owing to the undeniable synergistic and beneficial effects of polytherapy with VAL and STAT, pharmaceutical formulations as mixtures of these substances, in the form of two-component medications or polypills, might be expected soon. This was the motif to search for a simple, rapid and accurate method for the determination of these substances in a mixture. We have developed a derivative spectrophotometric method to be successfully applied to the analysis of binary mixtures of VAL and one of the examined statins. In the available literature, we have found no reports on spectrophotometric determination of binary mixtures described in this paper.

\section{EXPERIMENTAL}

\section{Instruments}

A spectrophotometer UV-VIS Cary 100 (Varian, Australia), Ultrasonic bath Elma (Schmidbauer GmbH, Germany) and centrifuge MPW 54 (MPW Med. Instruments, Poland) were used.

\section{Chemicals}

USP reference standards used were: valsartan (Sigma-Aldrich, USA), fluvastatin sodium (USP Convention, Rockville, MD, USA), pravastatin sodium (Sigma-Aldrich), atorvastatin calcium (Sigma-Aldrich).

Reagents and methanol of analytical grade quality were used.

\section{Pharmaceutical formulations}

Four pharmaceutical preparations were used: Avasart 160 (manufactured by Polfarmex S.A., Poland, one tablet contains $160 \mathrm{mg}$ of VAL), Lescol 20 (produced by Novartis Pharma GmbH, Germany, one capsule contains $21.06 \mathrm{mg}$ of fluvastatin sodium equivalent to $20 \mathrm{mg}$ of fluvastatin free acid), Pravator 20 (manufactured by Ranbaxy Sp. z o.o., Poland, one tablet contains $20 \mathrm{mg}$ of pravastatin sodium), Atorvasterol 20 (produced by Polpharma SA, Poland, one tablet contains $20 \mathrm{mg}$ of atorvastatin calcium).

\section{Standard and working solutions}

Standard solutions of the standard substances of VAL, FLU, PRV and ATR were prepared in methanol. 
For direct measurements, standard solutions were diluted with methanol in order to obtain working solutions in the concentration ranges (in $\mu \mathrm{g} \mathrm{mL} \mathrm{L}^{-1}$ ): 9.28-32.48 for VAL, 8.16 -28.56 for FLU, 9.6-48.00 for PRV and 14.40-39.90 for ATR.

\section{Analytical wavelengths for VAL and STAT}

Absorption spectra for VAL $(\gamma=3.92 \mu \mathrm{g} \mathrm{mL}-1)$, FLU $\left(\gamma=20.40 \mu \mathrm{g} \mathrm{mL} \mathrm{m}^{-1}\right)$, PRV $(\gamma=18.80$ $\left.\mu \mathrm{g} \mathrm{mL} \mathrm{m}^{-1}\right)$ and ATR $\left(\gamma=23.20 \mu \mathrm{g} \mathrm{mL}^{-1}\right)$ were recorded in UV using methanol as a blank. Absorption spectrum of VAL shows a poorly marked maximum at $251 \mathrm{~nm}$, FLV and ATR show their maxima close to $251 \mathrm{~nm}$ while PRV shows a well-defined maximum at $237 \mathrm{~nm}$. The obtained absorption spectra were converted into first, second and third order derivatives. Using the zero-crossing technique, analytical wavelengths were determined for appropriate derivatives and examined substances.

\section{Method validation}

The method was validated according to the ICH recommendations (26) and Polish Pharmacopoeia (27).

Linearity. - After transformation of the absorption spectra for VAL, FLU, ATR and PRV in concentration ranges (in $\mu \mathrm{g} \mathrm{mL}^{-1}$ ) of 9.28-32.48, 8.16-28.56, 14.40-39.90 and 9.60-48.00, resp., into derivative curves D1, D2, and D3, the derivative value was read at the specified wavelength and the relationship between the derivative value and concentration was plotted. The following tests were performed in order to verify the model of calibration: Mandel's $(p<0.05$ indicates the existence of a significant difference between the two models compared - linear and quadratic fit; $p>0.05$ indicates the equivalence of the two matches), Shapiro-Wilk (value of the statistic test $\mathrm{W}$ greater than the critical value allows to assume normal distribution), the Durbin-Watson and the Lagrange tests. The existence of autocorrelation of the residuals was verified.

Accuracy and intra-day precision. - The accuracy of the method was checked by determining the recovery using the standard addition method at three concentration levels (80, 100 and $120 \%$ of analyte concentration). The intra-day precision was checked at 50, 100 and $150 \%$ of analyte concentration. All measurements were repeated three times and the results were calculated using the appropriate regression equation. The obtained results were evaluated statistically.

Limit of detection (LOD) and limit of quantitation (LOQ). - LOD and LOQ were calculated using the following formulae: $L O D=3.3 S_{Y} / a$ and $L O Q=10 S_{Y} / a\left(S_{Y}-\right.$ residual standard deviation of the regression line, $a$-slope of the calibration line).

Selectivity. - Selectivity of the method with respect to binary mixtures of standard substance solutions was tested by determining the lack of influence of the substance copresent in the mixture on the value of the derivative of the primary component. Selectivity of the method in relation to a pharmaceutical formulation containing one active substance was checked by comparing its absorption spectrum after the active substance extraction process was performed, with the absorption spectrum of the standard solution of similar concentration. No differences confirmed the lack of influence of the excipients. 
M. Stolarczyk et al.: Spectrophotometric method for simultaneous determination of valsartan and substances from the group of statins in binary mixtures, Acta Pharm. 67 (2017) 463-478.

Laboratory prepared mixtures containing different ratios of VAL/FLU, VAL/ATR and $V A L / P R V$

Mixtures containing the following ratios of VAL/STAT 2:1; 1:1 and 1:2 were prepared in a series of volumetric flasks by accurately transferring different amounts of working solutions and filling them with methanol to a specified volume. Absorption spectra were then recorded in the range of 200-400 $\mathrm{nm}$. In the next step, absorption spectra were converted into derivatives of an appropriate order and values of derivatives were read at experimentally chosen wavelengths. The appropriate regression equation was used to calculate the concentration of the compound determined.

\section{Application to the analysis of pharmaceutical formulations}

VAL and the corresponding STAT were determined in commercially available pharmaceutical preparations (Avasart 160, Lescol 20, Pravator 20, Atorvasterol 20) using the developed method. Ten tablets of an appropriate preparation were powdered in a mortar and a portion of powder corresponding to one tablet was accurately weighed using an analytical balance. Weighed samples were transferred into 10.0-mL flasks and extracted with $10.0 \mathrm{~mL}$ of methanol by immersing them in an ultrasonic bath for $30 \mathrm{~min}$. The extract was then centrifuged for $15 \mathrm{~min}(1500 \mathrm{rpm})$ and filtered through a syringe filter $(0.45 \mu \mathrm{m})$. Solutions prepared in this way were then diluted to obtain the concentration of the analyzed substance in the linearity range. VAL and STAT concentrations in the samples were calculated using the appropriate regression equation. Five replicates were made for each pharmaceutical preparation.

\section{RESULTS AND DISCUSSION}

\section{Spectral characteristics}

None of the tested substances, with the exception of FLV, have a maximum in the range of 270-360 $\mathrm{nm}$ that could be used for quantitative analysis. Interference of spectra in the range of 200-280 nm makes direct determination of VAL in the presence of STAT difficult and does not ensure satisfying results according to the $\mathrm{ICH}$ requirements for spectrophotometric methods (Fig. 2). Interference of zero-order spectra of analytes significantly impedes direct simultaneous determination of VAL in the presence of FLV, PRV or ATR. Hence, derivative spectrophotometry with the "zero-crossing" technique was used in the course of analysis.

Conversion of zero-order spectra into derivatives causes their significant variation and the appearance of maxima that can be used for quantitative analysis of VAL and STAT mixtures. After evaluation of the first order (D1), second order (D2) and third order (D3) derivatives of the tested spectra and application of the "zero-crossing" method, it was found that in the case of a VAL-FLV mixture the determination may be successfully done using D1, D2 and D3 derivatives (Fig. 3).

In the case of the D2 derivative for the VAL-PRV mixture, it was not possible to determine zeros that could be used for quantitative analysis of the individual components and only D1 and D3 derivatives were used for determination (Fig. 4). Derivatives recorded for 
M. Stolarczyk et al.: Spectrophotometric method for simultaneous determination of valsartan and substances from the group of statins in binary mixtures, Acta Pharm. 67 (2017) 463-478.

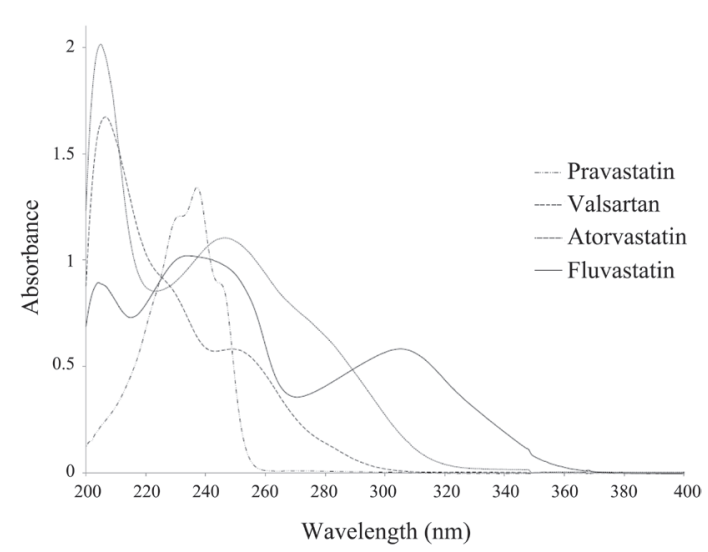

Fig. 2. Zero-order absorption spectra of VAL $\left(\gamma=3.92 \mu \mathrm{g} \mathrm{mL}^{-1}\right)$, FLU $\left(\gamma=20.40 \mu \mathrm{g} \mathrm{mL}^{-1}\right)$, PRV $(\gamma=18.80$ $\left.\mu \mathrm{g} \mathrm{mL} L^{-1}\right)$ and ATR $\left(\gamma=23.20 \mu \mathrm{g} \mathrm{m}^{-1}\right)$.

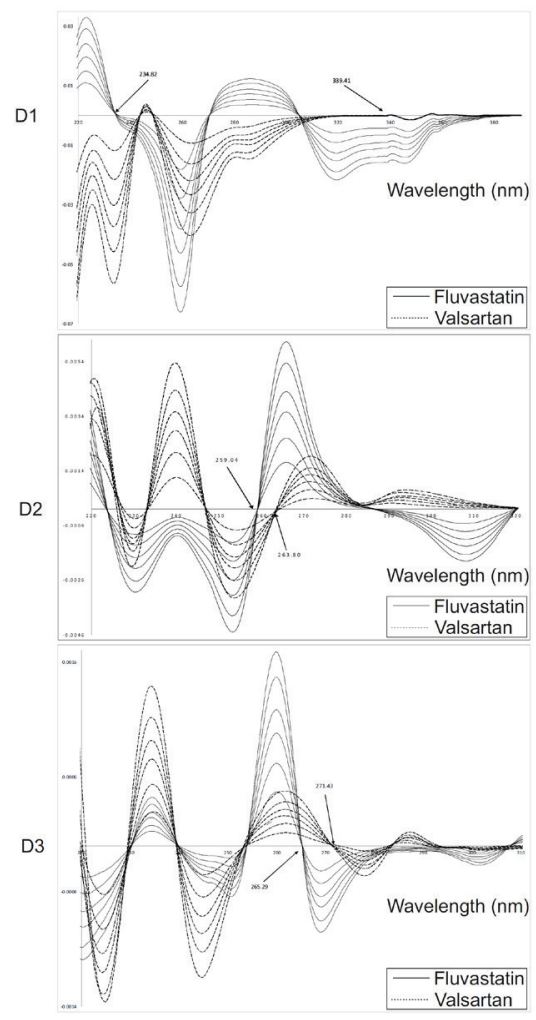

Fig. 3. D1, D2, D3 derivatives for standard solutions of VAL $(\gamma=9.28,13.92,18.54,23.20,27.84,32.48$ $\left.\mu \mathrm{g} \mathrm{mL}^{-1}\right)$ and FLU $\left(\gamma=8.16,12.24,16.32,20.40,24.48,28.56 \mu \mathrm{g} \mathrm{mL}^{-1}\right)$. 


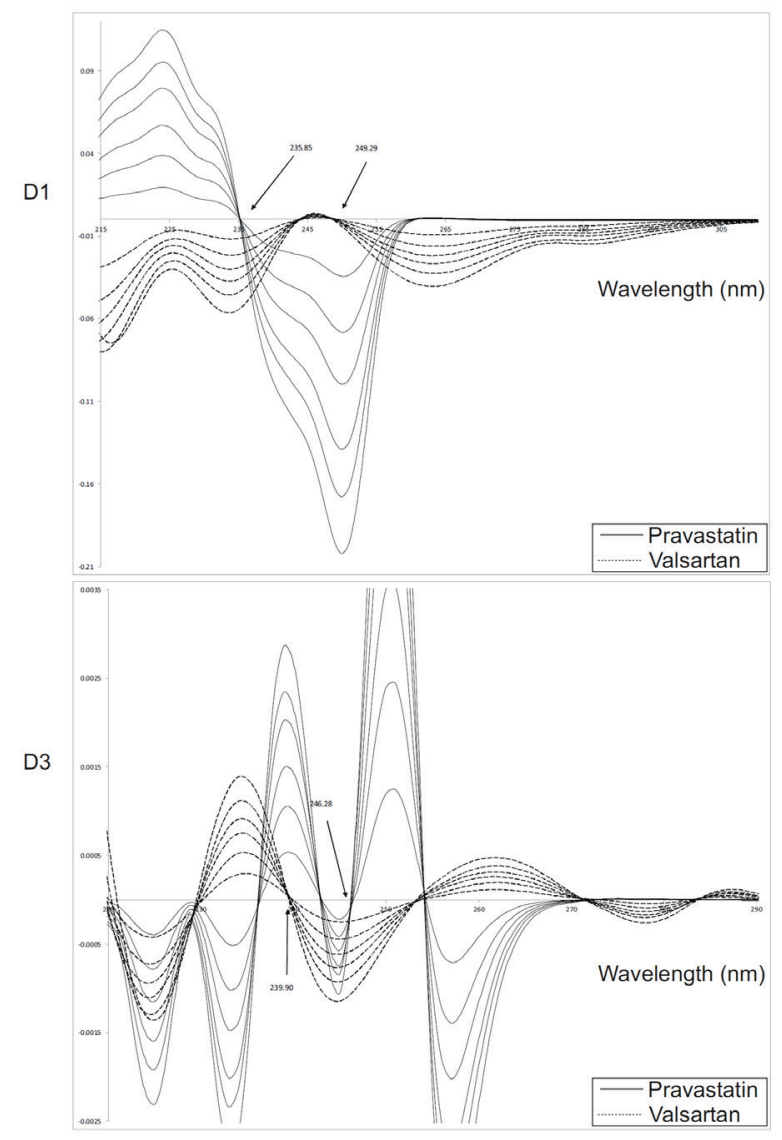

Fig. 4. D1 and D3 derivatives for standard solutions of VAL $(\gamma=9.28,13.92,18.54,23.20,27.84,32.48$ $\left.\mathrm{mg} \mu \mathrm{L}^{-1}\right)$ and PRV $(\gamma=9.6,19.2,28.8,38.4,48.0,57.60 \mu \mathrm{g} \mathrm{mL}-1)$.

the VAL-ATR mixture showed zeros useful for quantitative analysis only in the case of D2 and D3 derivatives (Fig. 5).

Analysis of the obtained derivatives allowed determining appropriate wavelengths. In the case of the determination of VAL and FLV, D1, D2 and D3 derivatives may be used. The following wavelengths were determined using the zero crossing method: D1 $\lambda=234.82 \mathrm{~nm}$, D2 $\lambda=259.04 \mathrm{~nm}$ and D3 $\lambda=265.29 \mathrm{~nm}$ for VAL and D1 $\lambda=339.41 \mathrm{~nm}, \mathrm{D} 2 \lambda=263.80 \mathrm{~nm}$ and D3 $\lambda=271.43 \mathrm{~nm}$ for fluvastatin. VAL and PRV can be determined only by using D1 and D3 derivatives, at the wavelength of D1 $l=235.85 \mathrm{~nm}$ and D3 $l=246.28 \mathrm{~nm}$ for VAL, and D1 derivative at $\lambda=249.29 \mathrm{~nm}$ and D3 derivative at $\lambda=239.90 \mathrm{~nm}$ for PRV. A mixture of VAL and ATR showed zeros in D2 and D3 derivatives and the optimal wavelengths were: D2 $\lambda$ $=273.20 \mathrm{~nm}$ and D3 $\lambda=245.96 \mathrm{~nm}$ for VAL, D2 $\lambda=246.77 \mathrm{~nm}$ and D3 $\lambda=239.90 \mathrm{~nm}$ for ATR. In addition, the course of the D3 derivatives has demonstrated the possibility to determine ATR or PRV at $l=239.90 \mathrm{~nm}$ in ternary mixtures, in the presence of VAL and FLV. 
M. Stolarczyk et al.: Spectrophotometric method for simultaneous determination of valsartan and substances from the group of statins in binary mixtures, Acta Pharm. 67 (2017) 463-478.

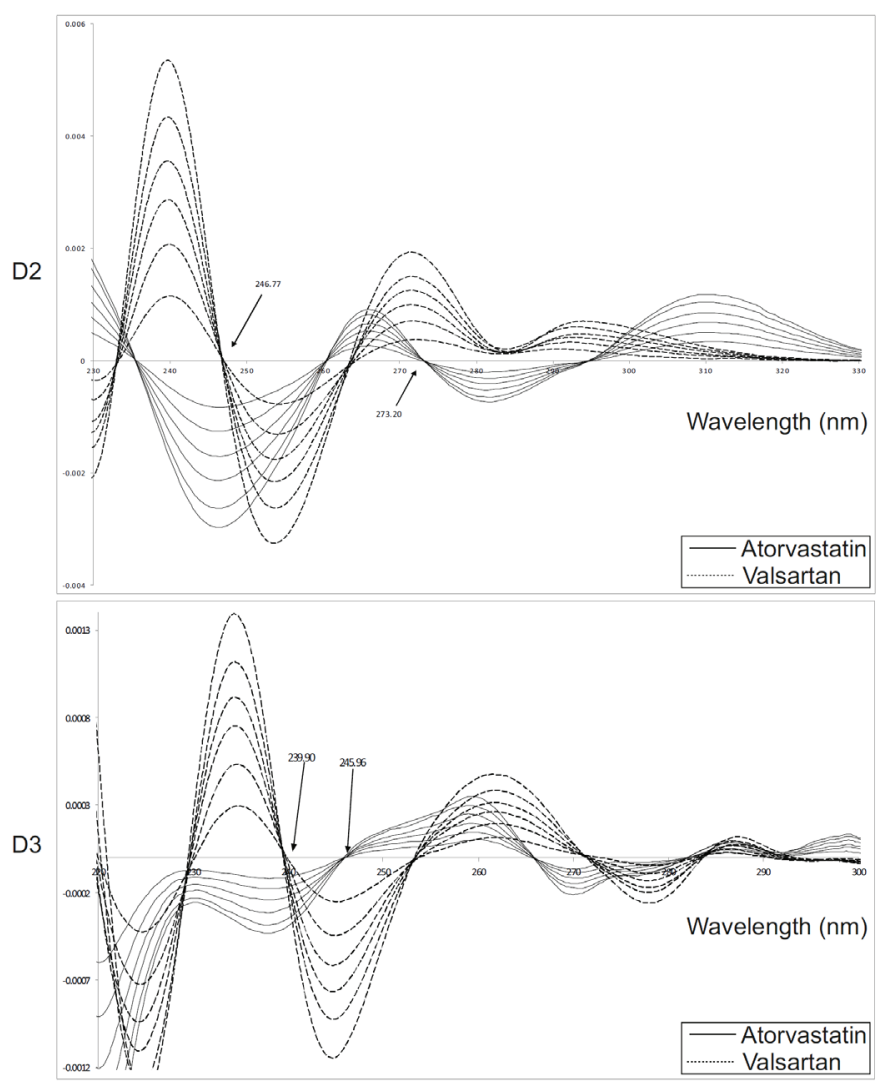

Fig. 5. D2 and D3 derivatives for standard solutions of VAL $(\gamma=9.28,13.92,18.54,23.20,27.84,32.48$ $\left.\mu \mathrm{g} \mathrm{mL}^{-1}\right)$ and ATR $\left(\gamma=14.40,17.10,22.80,28.50,34.20,39.90 \mu \mathrm{g} \mathrm{mL}^{-1}\right)$.

\section{Validation}

Validation results together with statistical evaluation are presented in Tables I and II.

Selectivity. - The absorption spectra recorded for solutions of pharmaceutical preparations after extraction did not differ from the absorption spectra of standard solutions. At the selected wavelengths, no additional extremes were observed that could affect the obtained results during analysis.

Linearity. - Linearity was found in the ranges of 9.28-32.48 $\mu \mathrm{g} \mathrm{mL}^{-1}$ for VAL, 8.16-28.56 $\mu \mathrm{g} \mathrm{mL} \mathrm{g}^{-1}$ for FLU, $9.60-48.00 \mu \mathrm{g} \mathrm{mL}^{-1}$ for PRV and $14.40-39.90 \mu \mathrm{g} \mathrm{mL}^{-1}$ for ATR. The determination coefficient for examined substances at the chosen analytical wavelengths was 0.98940.9995. The determined linearity ranges for analytes are given in Tables I and II. The tested concentration ranges provided the optimal absorbance values and allowed obtaining accurate analysis results. In order to verify the calibration model, linear and quadratic fits were 


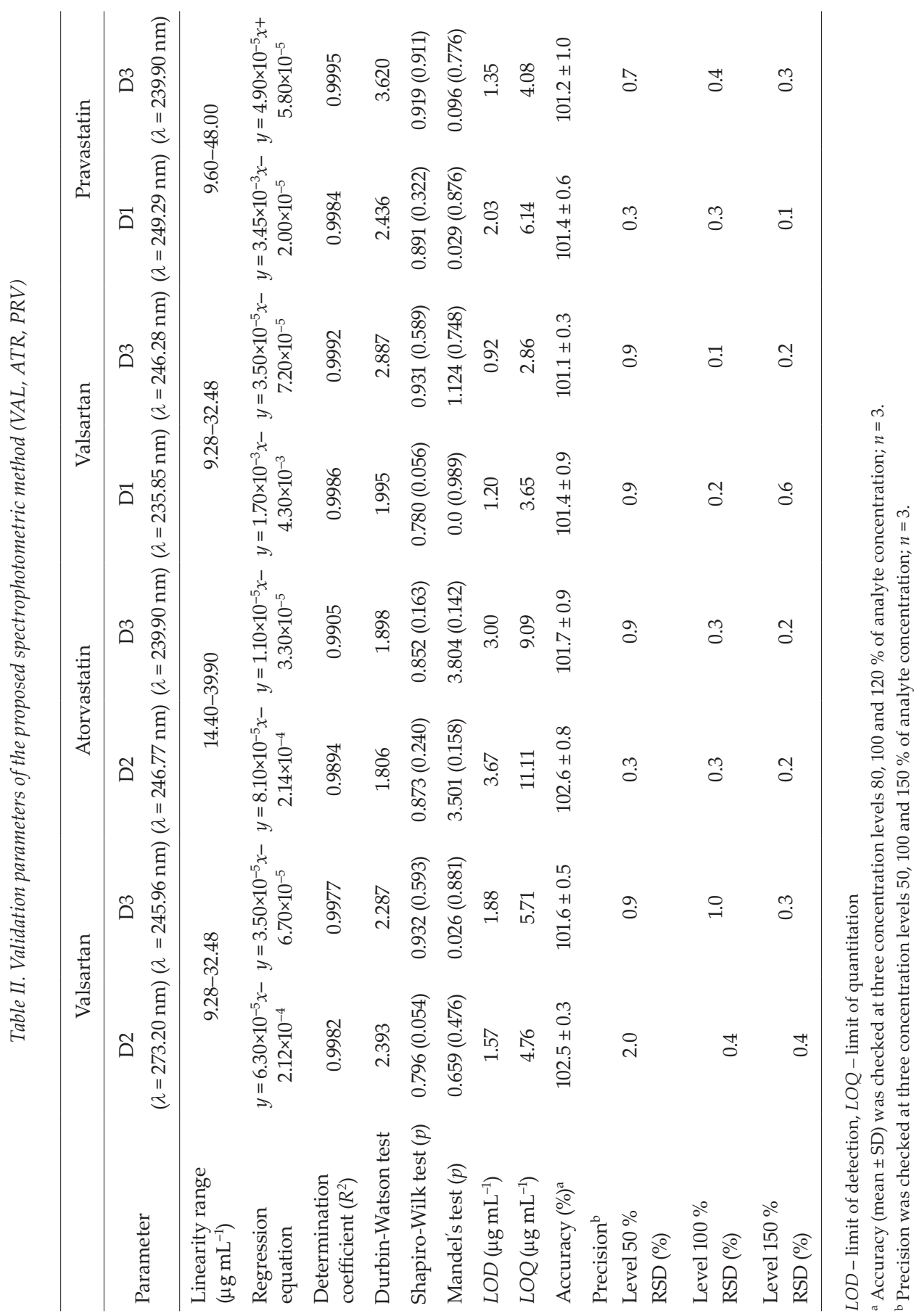


compared by Mandel's test and the results for all cases indicated equivalence of quadratic and linear models. Linear fit was selected for quantitative analyses. The assumption of normal distribution of residuals was confirmed by the Shapiro-Wilk test. The hypothesis of the lack of autocorrelation of random components was verified by the Durbin-Watson test. The results indicated no significant autocorrelation of the residual values for VAL and ATR for all derivatives and PRV D1 $(\lambda=249.20 \mathrm{~nm})$. In the case of linearity of FLV (for D1, D2 and D3) and PRV for D3 $(\lambda=239.90 \mathrm{~nm})$, the occurrence of significant autocorrelation was observed, but we decided to apply the linear fit because of higher values of $R^{2}$ than in the case of quadratic fit. The Lagrange test was used for the third derivative in the case of FLV $(\lambda=271.41$ $\mathrm{nm})$ and VAL $(\lambda=246.28 \mathrm{~nm})$, since the Durbin-Watson test was not conclusive.

Accuracy. - Percent recovery of the analytes at three concentration levels (80, 100 and $120 \%$ ) was within $100 \pm 5 \%$. It ranged from 98.8-103.2 for VAL and 99.6-100.6 \% for FLU (D1, D2 and D3), $101.4 \%$ (D1) and $101.2 \%$ (D3) for PRV, while it was 102.6 and $101.7 \%$ (D2 and D3, resp.) for ATR.

Sensitivity. - The method was characterized by high sensitivity. LOD was in the range of 1.57-3.67 $\mu \mathrm{g} \mathrm{mL} \mathrm{m}^{-1}$ for VAL, $0.85-1.50 \mu \mathrm{g} \mathrm{mL}^{-1}$ for FLV, $1.35-2.03 \mu \mathrm{g} \mathrm{mL} \mathrm{mL}^{-1}$ for PRV, 3.00-3.67 $\mu \mathrm{g} \mathrm{mL} \mathrm{m}^{-1}$ for ATR and the respective LOQs were: $2.86-8.33 \mu \mathrm{g} \mathrm{mL} \mathrm{m}^{-1}, 2.58-4.54 \mu \mathrm{g} \mathrm{mL}^{-1}$, 4.08-6.14 $\mu \mathrm{g} \mathrm{mL}^{-1}, 9.09-11.1 \mu \mathrm{g} \mathrm{mL}{ }^{-1}$, depending on the class of the derivative.

\section{Analysis of laboratory prepared mixtures}

Based on the determined analytical wavelengths for the individual substances and the order of the derivative and using the corresponding regression equations, quantitative analyses of the laboratory prepared mixtures were performed. The composition of mixtures was adjusted so that the VAL:STAT ratio was 2:1; 1:1 and 1:2. In this way, the lack of effect of the second component on the value of the derivative of the examined substance was also proven, even if their relative concentrations were significantly different from each other. This confirms the correct choice of the appropriate analytical wavelength. In the case of VAL-FLU, the obtained recovery was 97.6-102.2 \% for VAL and 95.4-103.0 \% for FLU, for VAL-PRV 98.8-101.2 \% for VAL and 97.6-101.2 \% for PRV, for VAL-ATR 98.6-102.4\% for VAL and 98.6$102.5 \%$ for ATR. In summary, the obtained results were satisfactorily, ranging between 95 and $102 \%$. The obtained results together with statistical evaluation are given in Table III.

\section{Analysis of pharmaceutical preparations}

The developed and validated method was applied to determination of active substances in pharmaceutical preparations. Results of the measurements of particular active compounds in Avasart 160, Lescol 20, Pravator 20 and Atorvasterol 20 were within the range of $95-105 \%$ of the content declared by the manufacturer. The obtained results were characterized by good precision and accuracy, as evidenced by the standard deviation and $95 \%$ confidence interval presented in Table IV. RSD values were within the range of $0.8-2.1$ $\%$. Assay results and statistical analysis are given in Table IV.

Both the validation parameters of the developed method and the results obtained from the assays of the components in mixtures and in pharmaceutical formulations were satisfactory and acceptable according to the ICH requirements for spectroscopic methods 


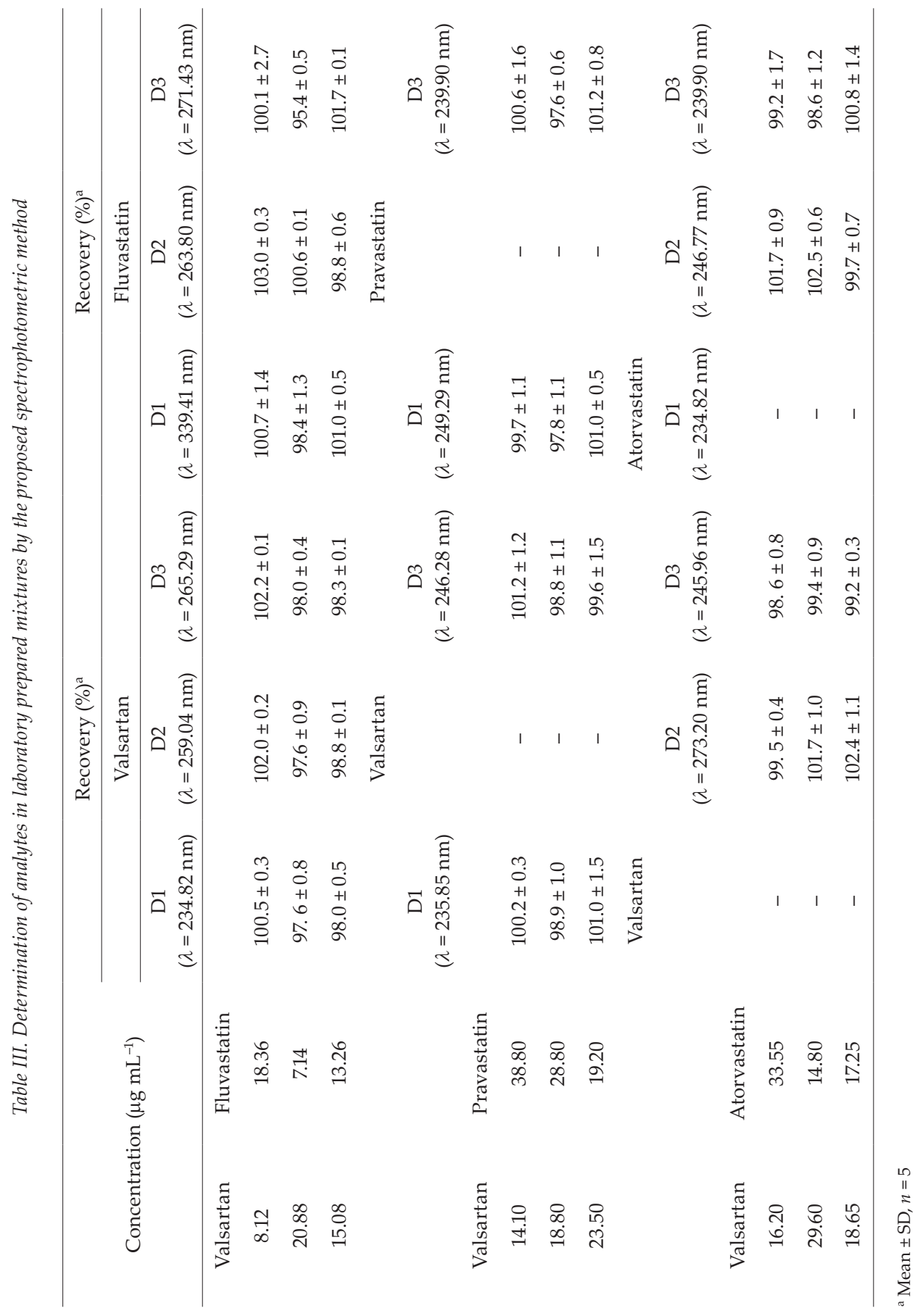


M. Stolarczyk et al.: Spectrophotometric method for simultaneous determination of valsartan and substances from the group of statins in binary mixtures, Acta Pharm. 67 (2017) 463-478.

Table IV. Determination of valsartan, pravastatin, fluvastatin and atorvastatin in pharmaceutical preparations by the proposed method

\begin{tabular}{|c|c|c|c|c|c|c|}
\hline \multirow[t]{2}{*}{$\begin{array}{l}\text { Pharmaceutical } \\
\text { preparation }\end{array}$} & \multicolumn{3}{|c|}{$\begin{array}{l}\text { Content found } \\
\text { (mean, } n=5) \\
\text { (mg per tablet) }\end{array}$} & \multicolumn{3}{|c|}{ Statistical assessment } \\
\hline & D1 & D2 & D3 & D1 & D2 & D3 \\
\hline $\begin{array}{l}\text { Avasart } 160 \\
\text { (VAL) }\end{array}$ & 159.71 & 160.36 & 160.37 & $\begin{array}{c}\mathrm{SD}=1.3 \\
t \cdot \mathrm{SEM}_{0.95}= \pm 1.6 \\
\mathrm{RSD}=0.8 \%\end{array}$ & $\begin{array}{c}\mathrm{SD}=1.8 \\
t \mathrm{SEM}_{0.95}= \pm 2.359 \\
\mathrm{RSD}=1.2 \%\end{array}$ & $\begin{array}{c}\mathrm{SD}=1.2 \\
t \cdot \mathrm{SEM}_{0.95}= \pm 1.5 \\
\mathrm{RSD}=0.8 \%\end{array}$ \\
\hline $\begin{array}{l}\text { Pravator } 20 \\
\text { (PRV) }\end{array}$ & 20.41 & - & 20.39 & $\begin{array}{c}\mathrm{SD}=0.1 \\
t \cdot \mathrm{SEM}_{0.95}= \pm 0.2 \\
\mathrm{RSD}=2.0 \%\end{array}$ & - & $\begin{array}{c}\mathrm{SD}=0.2 \\
t \cdot \mathrm{SEM}_{0.95}= \pm 0.2 \\
\mathrm{RSD}=1.8 \%\end{array}$ \\
\hline Lescol 20 (FLV) & 21.99 & 21.03 & 21.88 & $\begin{array}{c}\mathrm{SD}=0.8 \\
t \cdot \mathrm{SEM}_{0.95}= \pm 1.0 \\
\mathrm{RSD}=1.5 \%\end{array}$ & $\begin{array}{c}\mathrm{SD}=0.4 \\
t \cdot \mathrm{SEM}_{0.95}=0.2 \\
\mathrm{RSD}=1.9 \%\end{array}$ & $\begin{array}{c}\mathrm{SD}=0.4 \\
t \cdot \mathrm{SEM}_{0.95}= \pm 0.5 \\
\mathrm{RSD}=2.0 \%\end{array}$ \\
\hline $\begin{array}{l}\text { Atorvasterol } 20 \\
\text { (ATR) }\end{array}$ & - & 20.45 & 20.89 & - & $\begin{array}{c}\mathrm{SD}=1.0 \\
t \cdot \mathrm{SEM}_{0.95}= \pm 0.2 \\
\mathrm{RSD}=1.0 \%\end{array}$ & $\begin{array}{c}\mathrm{SD}=0.9 \\
t \cdot \mathrm{SEM}_{0.95}= \pm 0.3 \\
\mathrm{RSD}=1.2 \%\end{array}$ \\
\hline
\end{tabular}

$t \cdot t \cdot \mathrm{SEM}_{0.95}-$ margin of error

(26). The previously proposed spectrophotometric methods for the determination of valsartan (12) in a narrower linearity range showed similar RSD and LOD values. In this case, the analysis was using only the first-order derivative, which in some cases can significantly complicate the analysis process. The possibility of selection of the derivative allows optimizing the obtained results and selecting the appropriate procedure for a mixture of defined composition. Another procedure described in the literature was the spectrophotometric method that requires determination of the isosbestic point but the application of this procedure may be limited when there is no possibility to determine that point (13). In the case of determination of statins in pharmaceutical preparations by a spectrophotometric method, Ergin et al. (21) used the reaction of derivatization of statins with 7,7,8,8-tetracyanoquinodimethane, which, on the one hand, allowed the use of the VIS analysis but, on the other hand, significantly complicated the analysis process compared to the method using the zero-crossing technique. The application of separation techniques such as HPLC (22) gives a much larger linearity range and better validation parameters (method applied for the determinations in human serum) but when it was used for the assay in pharmaceutical formulations, slightly higher RSD values were obtained than with the spectrophotometric method described above. An additional advantage of the spectrophotometric method is the low cost and short time of the analysis. In the case of the HPLC method, the separation of examined substances on Inertsil ODS 3V column $(4.6 \times 250 \mathrm{~mm}, 5 \mu \mathrm{m})$ took about 40 minutes (22) while the time of spectrophotometric analysis that we propose does not exceed $1 \mathrm{~min}$. 


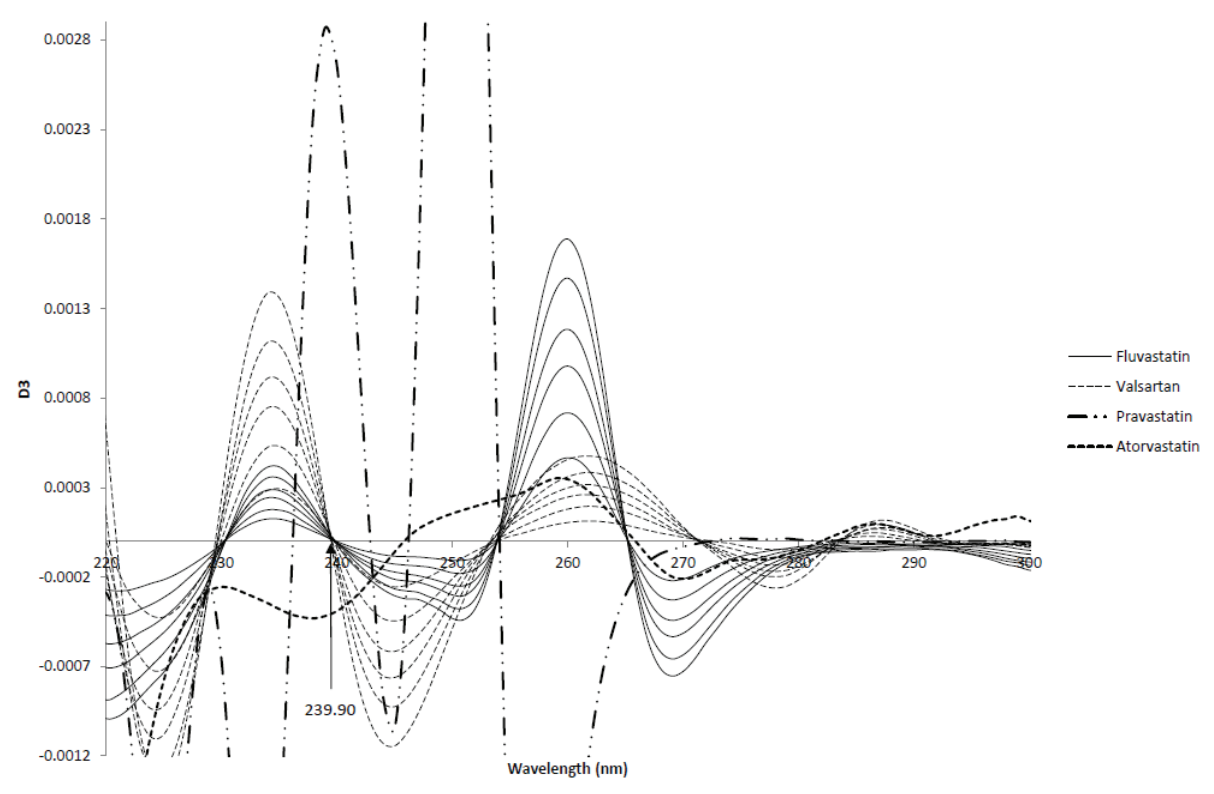

Fig. 6. D3 derivatives for standard solutions of VAL, FLV, ATR and PRV.

\section{Other applications}

Analysis of the derivatives showed that the third derivative of the absorption spectra of FLV and VAL showed zero at $\lambda=239.90 \mathrm{~nm}$. At this wavelength for PRV and ATR, the extremes occurred that are likely to be used for quantitative analysis of ternary mixtures containing FLV, VAL and ATR or FLV, VAL and PRV (Fig. 6).

\section{CONCLUSIONS}

The spectrophotometric method for simultaneous determination of a substance from the group of angiotensin receptor blockers, valsartan, and statins (fluvastatin, pravastatin or atorvastatin) was assessed. Achieving reliable results is possible by derivatization of zero-order spectra, using the „zero-crossing" method and selecting the appropriate order of the derivative and wavelength. Fulfilment of these conditions means that the method used is accurate, precise, sensitive and specific, as evidenced by the statistical parameters.

Based on the conducted measurements and statistical evaluation of the obtained results, it can be concluded that the proposed procedures can be useful for quantitative analysis of valsartan and statins both in model mixtures and in pharmaceutical preparations, being an alternative to expensive and time-consuming separation techniques.

The proposed method is simple, rapid, selective and sensitive and may be an alternative to chromatographic methods. 
M. Stolarczyk et al:: Spectrophotometric method for simultaneous determination of valsartan and substances from the group of statins in binary mixtures, Acta Pharm. 67 (2017) 463-478.

Acronyms/abbreviations. - VAL - valsartan, ATR - atorvastatin, FLV - fluvastatin, PRV - pravastatin, HMG-CoA - 3-hydroxy-3-methylglutaryl coenzyme-A reductase, STAT - statins, ARB - angiotensin receptor blocker.

\section{REFERENCES}

1. M. Lunder, M. Janić, B. Jug and M. Šabovič, The effects of low-dose fluvastatin and valsartan combination on arterial function: A randomized clinical trial, Eur. J. Intern. Med. 23 (2012) 261-266; https://doi.org/10.1016/j.ejim.2011.11.011

2. V. Savić, B. Eržen, M. Janić, M. Lunder, M. Boncelj, K. Kanc, A. Janež and M. Šabovič, Improvement of arterial wall characteristics by the low-dose fluvastatin and valsartan combination in type 1 diabetes mellitus patients, Diab. Vasc. Dis. Res. 10 (2013) 420-425; https://doi.org/10.1177/1479164113485102

3. M. Janić, M. Lunder, M. Prezelj and M. Šabovič, A combination of low-dose fluvastatin and valsartan decreases inflammation and oxidative stress in apparently healthy middle-aged males, J. Cardiopulm. Rehabil. Prev. 34 (2014) 208-212; https://doi.org/10.1097 /HCR.0000000000000027

4. R. C. Hermida, C. Calvo, D. E. Ayala and J. E. Lopez, OR-6: Administration time-dependent efficacy of valsartan-atorvastatin combination in hyperlipidemic patients with essential hypertension, Am. J. Hypertens. 18 (S4) (2005) 2A; https://doi.org/10.1016/j.amjhyper.2005.03.006

5. S. A. Hussein, H. M. El-Wadood, M. A. Abdallah and A. A. Khorshed, HPTLC with fluorescence densitometry for simultaneous determination of some angiotensin II receptor blockers in tablets and plasma, J. AOAC Int. 98 (2015) 354-360; https://doi.org/10.5740/jaoacint.14-179

6. D. Tsvetkova, D. Obreshkova and S. Ognjanov, Validation of TLC densitometry for simultaneous quality and quantity analysis of angiotensin II receptor antagonist losartan, telmisartan and valsartan, Chim. Pharm. 64 (2011) 39-44.

7. T. Inglot, A. Gumieniczek, L. Komsta and A. Kasinska, LC and principal component analysis in the lipophilicity study of seven angiotensin II-AT1 receptor antagonists (sartans), Chromatographia 68 (2008) 977-983; https://doi.org/10.1365/s10337-008-0801-5

8. J. Golubovic, A. Protic, B. Otasevic and M. Zecevic, Quantitative structure-retention relationships applied to development of liquid chromatography gradient-elution method for the separation of sartans, Talanta 150 (2016) 190-197; https://doi.org/10.1016/j.talanta.2015.12.035

9. K. C. Skai and A. P. Mazureki, Identification and determination of selected angiotensin II receptor antagonist group drugs by HPLC method, Acta Pol. Pharm. Drug Res. 68 (2011) 831-837.

10. S. Hillaert and W. V. den Bossche, Optimization and validation of a capillary zone electrophoretic method for the analysis of several angiotensin-II-receptor antagonists. J. Chromatogr. A 979 (2002) 323-333; https://doi.org/10.1016/S0021-9673(02)01247-5

11. S. Hillaert, T. R. M. De Beer, J. O. De Beer and W. V. den Bossche, Optimization and validation of a micellar electrokinetic chromatographic method for the analysis of several angiotensin-II-receptor antagonists, J. Chromatogr. A 984 (2003) 135-146; https://doi.org/10.1016/S0021-9673(02)01832-0

12. S. Zargar and T. A. Wani, New UPLC-MS/MS method for simultaneous determination of telmisartan and hydrochlorthiazide in human plasma, Lat. Am. J. Pharm. 33 (2014) 432-440.

13. E. Şatana, S. Altinay, N. G. Göger, S. A. Özkan and Z. Şentürk, Simultaneous determination of valsartan and hydrochlorothiazide in tablets by first-derivative ultraviolet spectrophotometry and LC, J. Pharm. Biomed. Anal. 25 (2001) 1009-1013; https://doi.org/10.1016/S0731-7085(01)00394-6

14. M. M. Deshpande, M. P. Mahajan and S. D. Sawant, Simultaneous estimation of valsartan and hydrochlorothiazide in fixed dose combination in UV spectrophotometry, Int. J. Pharm. Sci. Res. 3 (2012) 236-240.

15. T. A. Wani, A. Ahmad, S. Zargar, N. Y. Khalil and I. A. Darwish, Use of response surface methodology for development of new microwell-based spectrophotometric method for determination of atorvastatin calcium in tablets, Chem. Cent. J. 6 (2012) 134-142; https://doi.org/10.1186/1752-153X-6-134 
16. I. Muszalska, A. Sobczak, A. Dołhaand and A. Jelińska, Analysis of sartans: A review, J. Pharm. Sci. 103 (2014) 2-28; https://doi.org/10.1002/jps.23760

17. M. S. Tahir, A. Adnan and Q. Syed, Chromatographic resolution of angiotensin II receptor antagonists (sartans), J. Chromatogr. B 1027 (2016) 57-63; https://doi.org/10.1016/j.jchromb. 2016.05.023

18. A. Nakashima, C. Saxer, M. Niina, N. Masuda, K. Iwasaki and K. Furukawa, Determination of fluvastatin and its five metabolites in human plasma using simple gradient reversed-phase highperformance liquid chromatography with ultra-violet detection, J. Chromatogr. B 760 (2001) 17-25; https://doi.org/10.1016/S0378-4347(01)00250-X

19. F. P. Gomes, P. L. Garcia, J. M. P. Alves, A. K. Singh, E. R. M. Kedor-Hackmann and M. I. R. M. Santoro, Development and validation of stability-indicating HPLC methods for quantitative determination of pravastatin, fluvastatin, atorvastatin and rosuvastatin in pharmaceuticals, Anal. Lett. 42 (2009) 1784-1804; https://doi.org/10.1080/00032710903060669

20. E. Kublin, E. Malanowicz, B. Kaczmarska-Graczyk, K. Czerwińska, E. Wyszomirska and A. P. Mazurek, Development of chromatographic method for determination of drugs reducing cholesterol level - statins and ezetimibe, Acta Pol. Pharm. Drug Res. 72 (2015) 429-437.

21. J. L. Yan, Determination of fluvastatin sodium by differential pulse voltammetry, Pak. J. Biol. Sci. 9 (2006) 2156-2158.

22. M. P. S. Neves, P. A. Nouws and C. Delerue-Matos, Direct electroanalytical determination of fluvastatin in a pharmaceutical dosage form: Batch and flow analysis, Anal. Lett. 41 (2008) 2794-2804; https://doi.org/10.1080/00032710802421889

23. G. Ergin, S. Çağlar, A. Önal and S. E. Toker, Spectrophotometric determination of 3-hydroxy-3methylglutaryl coenzyme-A reductase inhibitors in pharmaceutical preparations, Turk. J. Chem. 37 (2013) 171-181.

24. K. Pasha, S. Muzeeb, S. J. S. Basha, D. Shashikumar, R. Mullangi and N. R. Srinivas, Analysis of five HMG-CoA reductase inhibitors - atorvastatin, lovastatin, pravastatin, rosuvastatin and simvastatin: pharmacological, pharmacokinetic and analytical overview and development of a new method for use in pharmaceutical formulations analysis and in vitro metabolism studies, Biomed. Chromatogr. 20 (2006) 282-293; https://doi.org/10.1002/bmc.561

25. S. Ertürk, A. Önal and S. M. Çetin, Analytical methods for the quantitative determination of 3-hydroxy-3-methylglutaryl coenzyme A reductase inhibitors in biological samples, J. Chromatogr. B. 793 (2003) 193-205; https://doi.org/10.1016/S1570-0232(03)00314-3

26. International Conference on Harmonisation of Technical Requirements for Registration of Pharmaceuticals for Human Use, ICH Harmonised Tripartite Guideline, Validation of Analytical Procedures: Text and Methodology Q2(R1), Current Step 4 version, Geneva November 2005; http://www.ich.org/ fileadmin/Public_Web_Site/ICH_Products/Guidelines/Quality/Q2_R1/Step4/Q2_R1__Guideline. pdf; last access date April 22, 2017.

27. Polish Pharmacopoeia, $\mathrm{X}^{\text {th }}$ ed., Office for Registration of Medicinal Products, Medical Devices and Biocidal Products, Warszawa 2016. 